\title{
THE DIAGNOSIS OF MITRAL INCOMPETENCE FROM LEFT ATRIAL PRESSURE CURVES
}

\author{
BY \\ BERTRAND G. WELLS \\ From St. Bartholomew's Hospital \\ Received August 12, 1957
}

Changes in the atrial pressure curves are known to occur in mitral or tricuspid incompetence. Although there are many reports of such changes there has been no attempt to determine whether they can indicate the degree of valvular incompetence that is present. The review of these reports has therefore been brief.

Mackenzie (1910) described changes in the venous pulse in tricuspid incompetence. These changes were confirmed by Wiggers (1923) and Bloomfield et al. (1946). McCord and Blount (1952) described an obliteration of the $x$ descent by an early systolic pressure rise. They postulated that the height of the $v$ wave should form a basis for the estimation of the severity of tricuspid incompetence.

The study of the changes in left atrial pressure in mitral incompetence is more recent. Wiggers and Feil (1922) described changes in the left atrial pressure curve in dogs when temporary mitral incompetence was produced. Similar changes were reported by Haring et al. (1956) who noted that there were slight differences between the wedge pressures and the true left atrial pressures. Despite these differences much of the study of left atrial pressure changes in man has been made from wedge pressure tracings.

Several workers have considered that a tall broad $\mathbf{v}$ wave is typical of mitral incompetence (Gorlin et al., 1952; Wade et al., 1952; Biörck et al., 1953). Others have stressed the importance of the obliteration of the $x$ descent (Lagerlöf and Werkö, 1949; Husfeldt and Warburg, 1952; Gérard and Benyamine, 1956). Dexter et al. (1950) felt that wedge pressure curves might indicate the degree of mitral incompetence. Finally it has been suggested (Owen and Wood, 1955) that the rate of $y$ descent divided by the height of the preceding $v$ wave might, by denying the existence of significant stenosis, indicate the presence of mitral incompetence.

On the other hand a number of workers have stated that the changes in wedge pressure tracings are of little value in determining whether or not there is significant mitral incompetence (Wynn et al, 1952; Venner and Holling, 1953; and Soulié et al., 1954). Eliasch (1952) considered that a tall $\mathrm{v}$ wave did not always indicate mitral incompetence but might be due to pulmonary hypertension. Logan and Turner (1953) found that the shape of the wedge pressure curve did not help them to diagnose mitral incompetence. A similar view was held by Burchell and Edwards (1953). McGreggor and Zion (1955) described a case of almost pure mitral incompetence with a normal wedge pressure tracing.

The inaccuracies of wedge pressure tracings have been eliminated by direct puncture of the left atrium (Björk, 1955). Various results have been obtained in mitral incompetence. It has been stated (Kent et al., 1955) that when the v wave exceeded the c wave by $5 \mathrm{~mm}$. $\mathrm{Hg}$ or more there was mitral incompetence. Other studies (Musser et al., 1956) have failed to confirm this. Bücherl (1956) described a single systolic peak with no $x$ descent. Fox et al. (1956) describing pressure tracings taken at operation considered that mitral incompetence abolished the $x$ descent and caused a very tall $\mathrm{v}$ wave with a steep descending limb. 
Opinions thus differ as to whether mitral incompetence can be diagnosed from left atrial pressure curves, and the present study has been made to establish what correlation exists between the features of the left atrial pressure curve and the degree of mitral incompetence. The material has also been examined to see whether some modification or combination of the features already described would provide a better correlation.

\section{MATERIAL AND METHOD}

Pressure tracings were taken at operation on seventy-seven patients with mitral valve disease. The surgeon was Mr. O. S. Tubbs or Mr. I. M. Hill. In most cases two observations were made on each patient, one before and one after valvotomy. Thus there were seventy-seven observations before valvotomy and seventy-three after. Fifty observations were on valves found to be incompetent and one hundred on valves showing no incompetence. The patients undergoing surgical treatment were consecutive, except for five observations on valves without incompetence which were omitted in order to obtain a round figure of 100 for the controls. All the patients had mitral stenosis which was relieved by valvotomy. In the fifty observations on patients with mitral incompetence, this was present before valvotomy in the majority and only occasionally was it produced by valvotomy: two of the six observations on valves with severe incompetence were made before valvotomy. One remained severe after valvotomy while the other became only moderate.

Needles were inserted into the left atrium and the left ventricle after thoracotomy and pressure curves with synchronous electrocardiogram were taken with a Sanborn electromanometer and twin Viso-cardiette. The manometer was switched from the atrial to the ventricular needle allowing two heart beats to be recorded from each chamber before switching back to the other. In this way comparable cardiac cycles were obtained, which were superimposed with the help of the electrocardiogram by tracing onto transparent paper. The sensitivity used was $25 \mathrm{~mm} . \mathrm{Hg}$ per $\mathrm{cm}$. and the paper speed $25 \mathrm{~mm}$. per second. In addition, a higher sensitivity $(10 \mathrm{~mm} . \mathrm{Hg}$ per $\mathrm{cm}$.) was used to study the curves in greater detail. The baseline was recorded before and after the curves by holding the needle outside the centre of the chamber concerned. The pulmonary arterial pressure was measured in each patient by needle puncture.

The following measurements were recorded at each observation.

(1) The atrial pressure just preceding the a or $\mathrm{c}$ wave.

(2) The extent of rise of $c$ wave.

(3) The atrial pressure at the $x$ descent or, if this was absent, at the end of the first third of ventricular systole.

(4) The height of the $v$ wave.

(5) The time from the onset of descent of the $v$ wave to the nadir of the $y$ descent.

(6) The level of the nadir of the y descent.

(7) The left ventricular systolic pressure.

(8) The pulmonary arterial pressure.

The surgeon palpated the mitral orifice at each observation and recorded the size of the opening and the degree of mitral incompetence present. The latter was described as none, very slight, slight, moderate, or severe. These were termed respectively grades 0 to 4 .

\section{RESULTS}

The material was first analysed according to the criteria suggested by previous workers. The height of the $\mathrm{v}$ wave, the $\mathrm{v}-\mathrm{c}$ difference, and the $\mathrm{Ry} / \mathrm{v}$ ratio were determined and each was contrasted with the degree of mitral incompetence found.

The height of the $\mathrm{v}$ wave is clearly of little importance if it is measured as an absolute pressure, for it would be elevated in pure mitral stenosis with a high left atrial pressure. The $v$ wave was therefore measured from the atrial pressure immediately preceding the a or c wave. This was not 
necessarily the lowest atrial pressure in ventricular diastole for there was occasionally a gradual rise between the y descent and the a or c wave. The results shown in Fig. 1 indicate that tall v waves do not necessarily indicate mitral incompetence and small ones do not necessarily indicate its absence.

The height of the $\mathrm{v}$ wave above the $\mathrm{c}$ wave ( $\mathrm{v}-\mathrm{c}$ difference) was next considered. Kent et al. (1955) suggested that figures of $5 \mathrm{~mm}$. $\mathrm{Hg}$ or more indicated the presence of mitral incompetence. An analysis of the present series on these lines is shown in Fig. 2. The cases of severe mitral incompetence all showed a $\mathrm{v}-\mathrm{c}$ difference of over 5 but so do many cases with little or no incompetence.

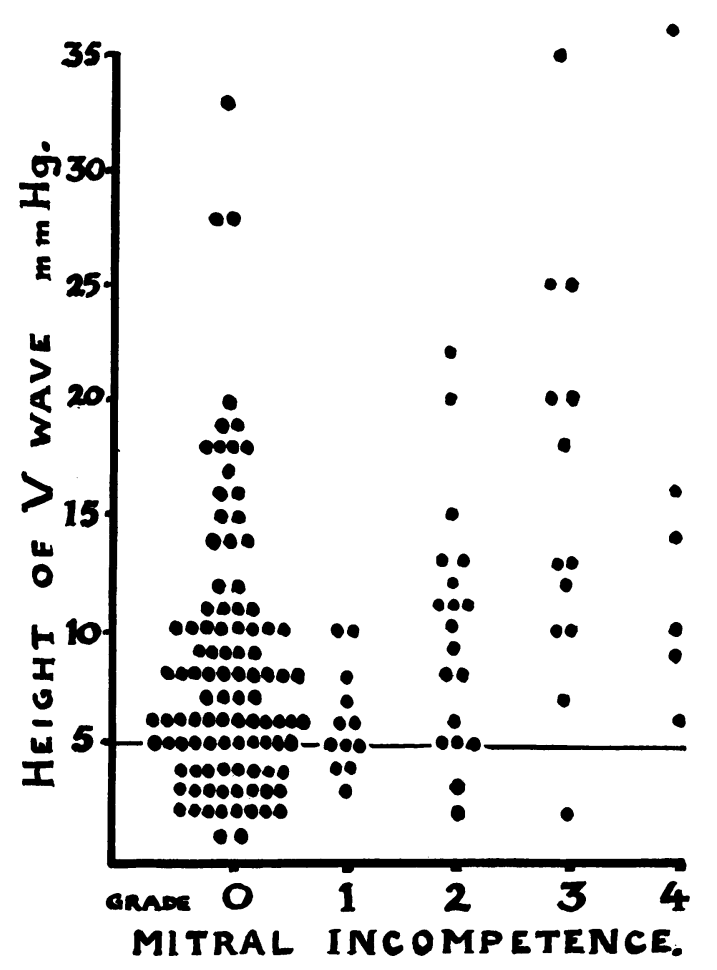

FIG. 1.-The height of the $v$ wave was taken as the height of the apex of this wave above the atrial pressure just prior to the a or c wave. The grades 0 to 4 of mitral incompetence were assessed, by palpation of the mitral orifice, as none, very slight, slight, moderate, and severe. As all the observations were at operations for mitral stenosis none of the regurgitant streams was of the size found in pure mitral incompetence.

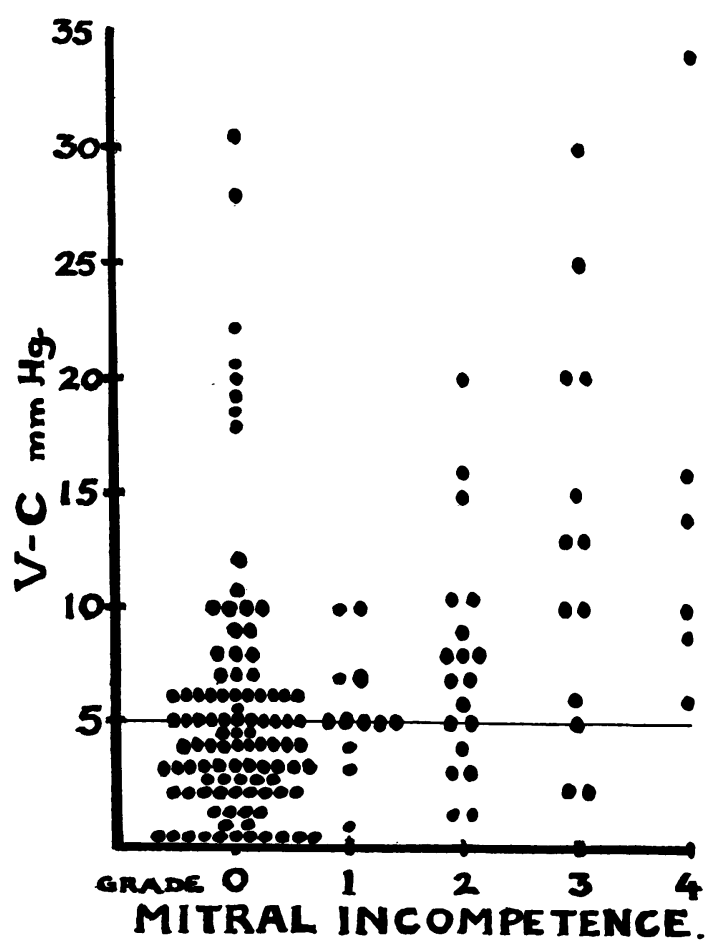

FIG. 2.-The "V-C difference" is the maximum height of the $\mathrm{v}$ wave minus the maximum height of the $c$ wave. The grades of mitral incompetence are as for Fig. 1.

The Ry/v (Owen and Wood, 1955) was next calculated in each case and the results were compared with the degree of mitral incompetence in Fig. 3. A considerable number of those with pure stenosis had $\mathrm{Ry} / \mathrm{v}$ ratios of over $1 \cdot 6$, and this method was therefore considered unsuitable for the diagnosis of mitral incompetence.

In the present series none of these methods has proved of much value in diagnosing mitral incompetence from atrial pressure tracings. The material was therefore examined to see whether any new criteria would be more helpful.

Although the peaks of the $c$ and $v$ waves do not help in the identification of mitral incompetence the fall between the two appears to be of greater significance. This $\mathrm{x}$ descent is sometimes abolished 


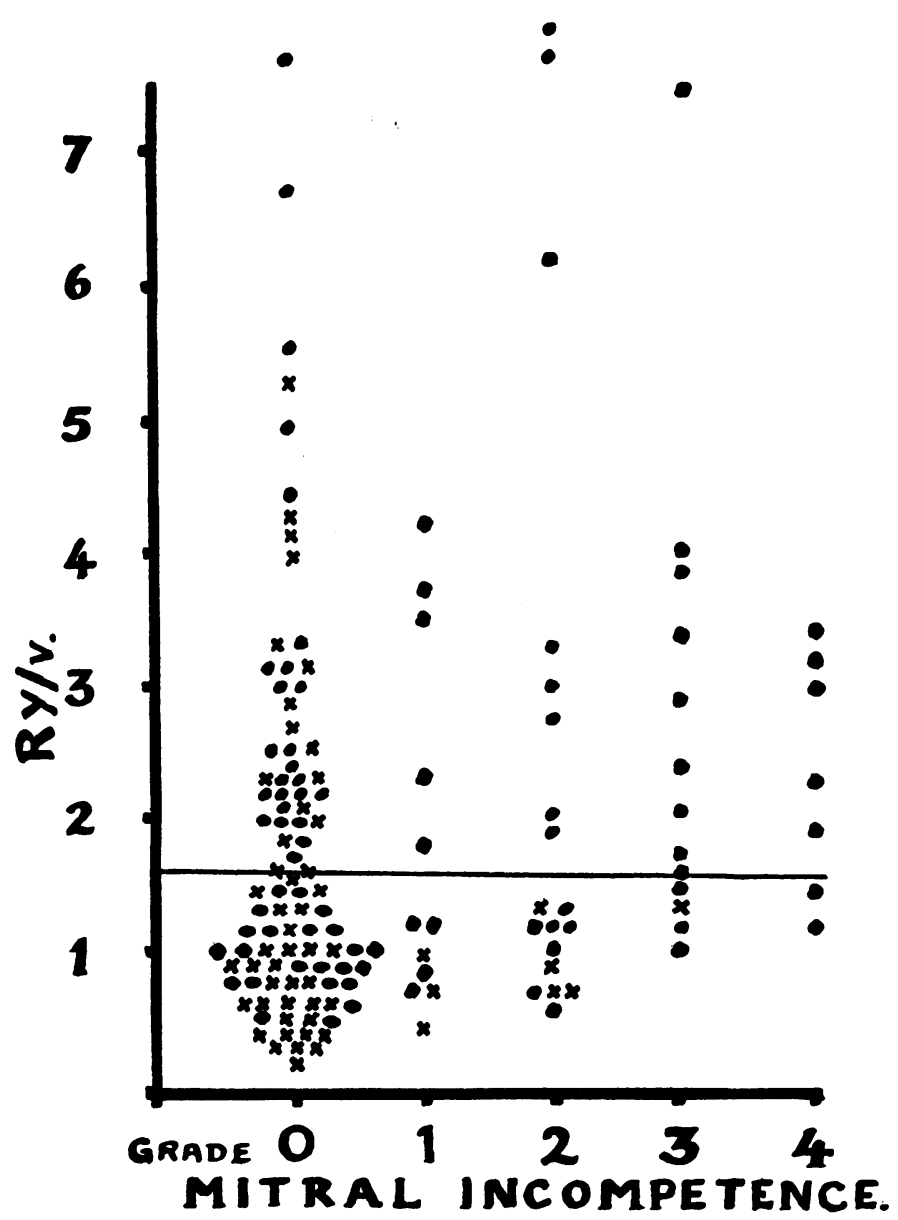

FIG. 3.-The $R y / v$ ratio is the height of the $v$ wave above the $y$ nadir divided by the product of the height of the $v$ wave and the time between the beginning of the descent of the $v$, and the $y$ nadir. A figure of 1.6 or over is said to deny the existence of significant stenosis. Those cases with mitral orifice area of under $1 \mathrm{sq} . \mathrm{cm}$. (length $x$ breadth) are marked with a cross. The grades of mitral incompetence are as for Fig. 1.

in mitral incompetence as is shown in Fig. 4. At other times it is present but reduced in size. In mitral stenosis without incompetence the $\mathbf{x}$ descent is often clear despite the presence of tall $\mathbf{v}$ waves, as is the case in Fig. 5. In other cases the $x$ descent appears to be reduced because of the presence of a large $c$ wave as can be seen in Fig. 6. Such a $\mathrm{c}$ wave is synchronous with the rise of ventricular pressure and must not be confused with the delayed rise of pressure that occurs in mitral incompetence (Fig. 4). This difference is important and can only be established when the pressure tracings are free from excessive damping.

The term "corrected $\mathrm{x}$ descent" has been used to describe the measurement made in this study. The $\mathrm{x}$ descent was measured when there was a distinct nadir at about the end of the first third of ventricular systole. When such a nadir was absent, the atrial pressure was measured at the end of the first third of ventricular systole. From the figure obtained was subtracted the atrial pressure just prior to the a or $\mathrm{c}$ wave, and also the height of the $\mathrm{c}$ wave (the number of $\mathrm{mm} . / \mathrm{Hg}$ of synchronous rise of atrial and ventricular pressure). The "corrected $\mathrm{x}$ descent" was occasionally a 


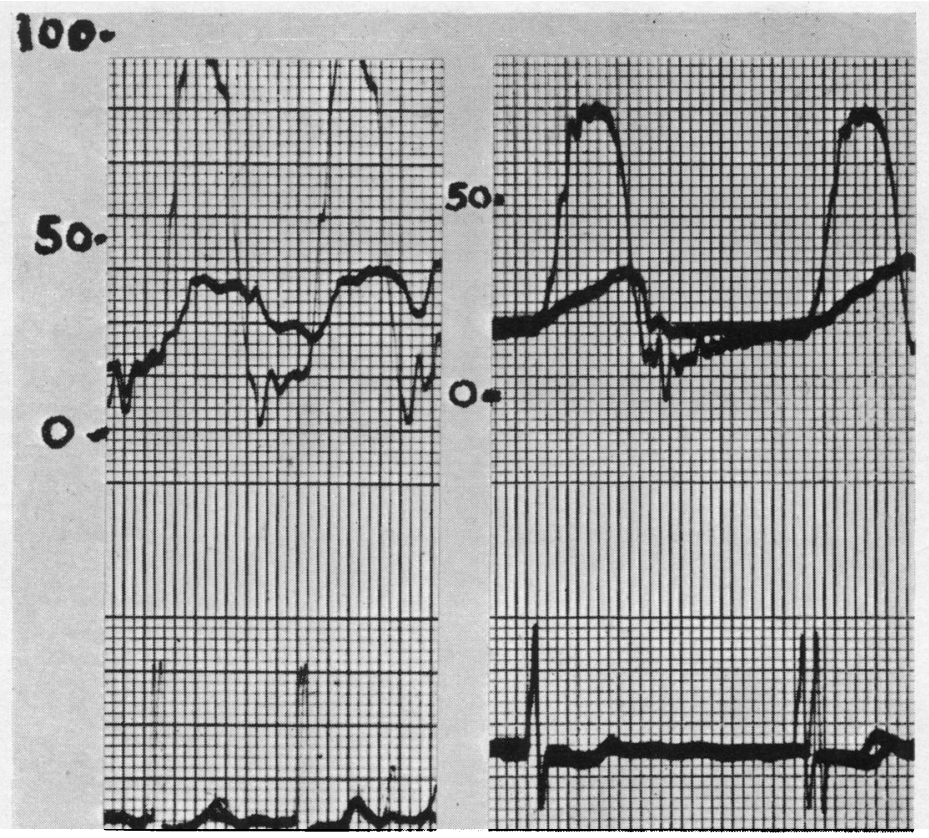

Fig. 4.-Superimposed atrial and ventricular pressure curves in two cases of severe mitral incompetence with atrial fibrillation. The $x$ descent is abolished but the $\mathbf{v}$ wave is not higher than in the cases of pure mitral stenosis shown in Fig. 5. Note. The study was made from pressure curves superimposed by a tracing-paper technique described in the text. For the purposes of Fig. 4 to 6 the curves, taken consecutively, were superimposed photographically. This is why the electrocardiogram has a double outline.

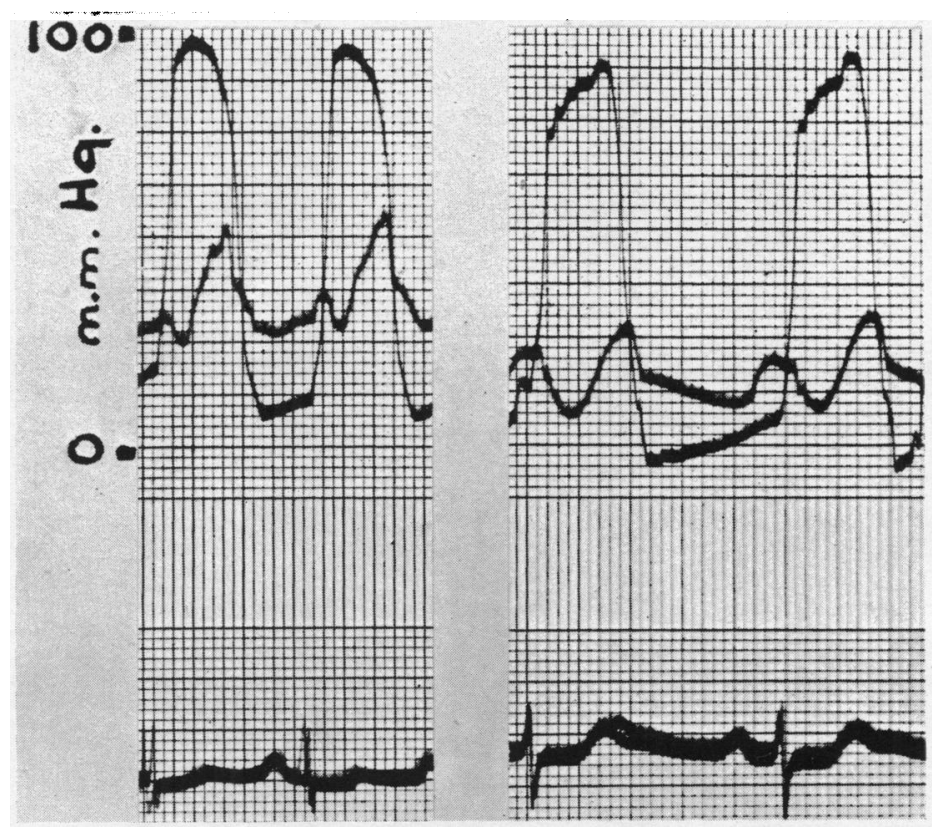

FIG. 5.-Superimposed atrial and ventricular pressure curves in two cases of mitral stenosis with sinus rhythm. The $x$ descent reaches about as low as the pressure just before the a wave. Although the $v$ waves are tall there is no mitral incompetence. 

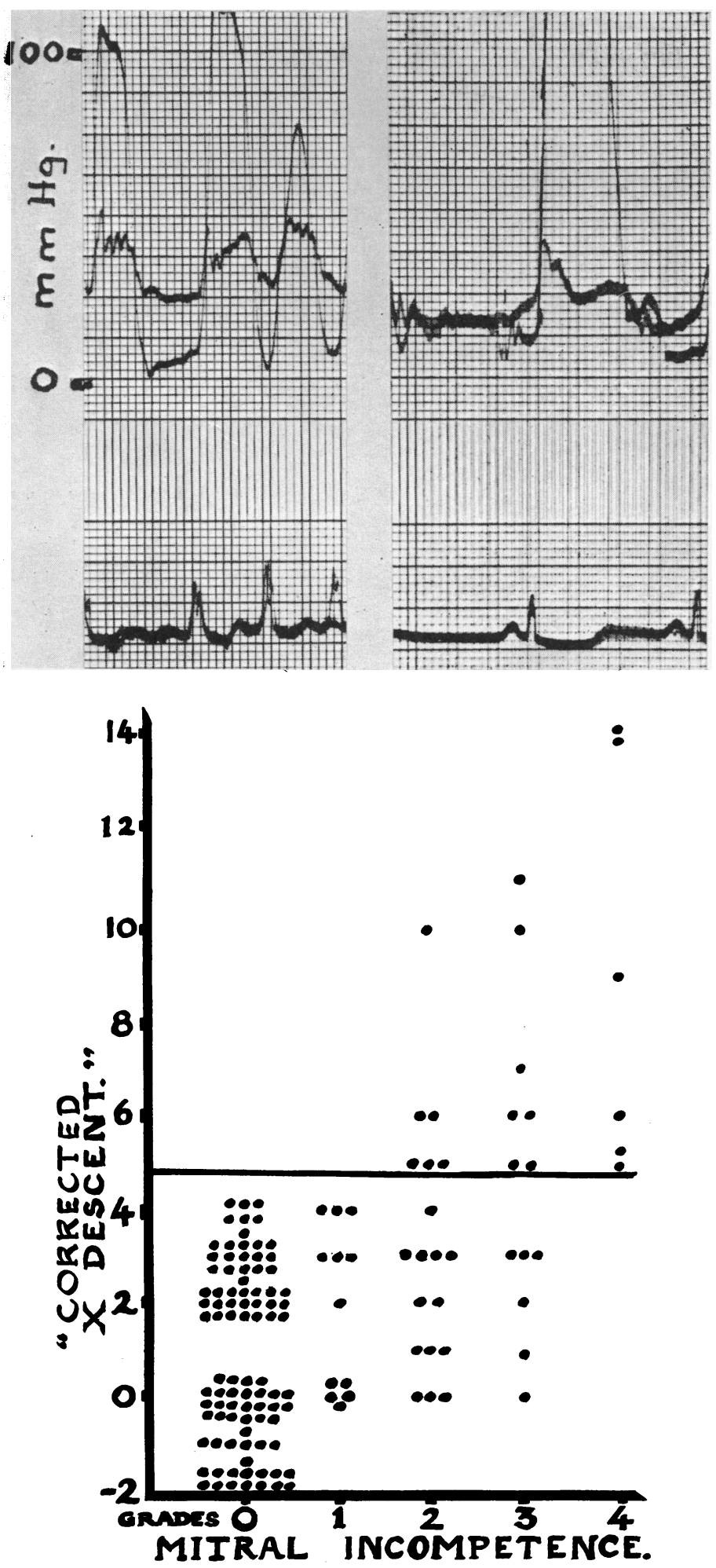

FIG. 6.-Superimposed atrial and ventricular pressure curves in two cases of mitral stenosis with no regurgitant stream. In these curves the $c$ waves are tall and do not have the same significance as the delayed pressure rise of the curves in Fig. 4.
FIG. 7.-The "corrected $\mathrm{x}$ descent" is calculated as follows. From the $x$ nadir are subtracted: (1) the pressure just prior to the a or c wave; (2) the number of $\mathrm{mm}$. $\mathrm{Hg}$ of synchronous rise of atrial and ventricular pressure. When there is no $\mathrm{x}$ descent the atrial pressure is measured at the end of the first third of ventricular diastole. The grades of mitral incompetence are as for Fig. 1. 
negative figure when the $c$ wave was of considerable size. The results are shown in Fig. 7. An elevation above $5 \mathrm{~mm}$. $\mathrm{Hg}$ means mitral incompetence. It was consistently present in severe incompetence and never seen when incompetence was either very slight or absent. A "corrected $x$ descent" of less than $5 \mathrm{~mm}$. $\mathrm{Hg}$ was sometimes present when incompetence was slight or moderate and was consistently present when it was very slight or absent.

\section{Discussion}

The height of the $\mathrm{v}$ wave does not indicate the presence of mitral incompetence. The present study shows that the $\mathrm{v}$ wave may be small in mitral incompetence and is sometimes tall in the absence of incompetence. There are many possible reasons for this. They are best explained by considering the factors concerned in the formation of the $\mathrm{v}$ wave. In health this wave is attributed to the filling of the atrium when the A-V valve is closed. The $\mathrm{v}$ wave does not reach its greatest height until the time of A-V opening and starts to fall at this time. When a tall $v$ wave is present in mitral stenosis the peak is earlier and a considerable fall occurs before the ventricular and atrial curves cross (Fig. 5). This difference of pattern indicates that the filling of the left atrium is not the important factor in the production of a large $\mathrm{v}$ wave in mitral stenosis. Some workers attribute this wave to the pressure on the left atrium and pulmonary veins of the pulmonary artery and its branches. This explanation is not satisfactory because the large $\mathbf{v}$ wave does not diminish in ventricular extrasystoles that fail to open the pulmonary valves. It is more likely that the pressure wave is due to the contraction of the atrioventricular ring and the pressure on the large atrium of the contracting ventricles. Such a contraction would be more effective in raising the atrial pressure if the initial atrial pressure were already high, or if the ventricular contraction were increased by some factor like aortic incompetence. The degree of pressure rise must also be affected by the size and distensibility of the left atrium itself. Another factor affecting the height of the $\mathrm{v}$ wave is the mobility of the mitral valve cusps. Freely mobile cusps should cause the $\mathrm{c}$ wave to be large and unless the cusps are drawn down by the papillary muscles the pressure rise would persist until the time of A-V opening. Finally, any variation of stroke volume would affect the height of the $\mathrm{v}$ wave as it does in the normal heart.

The numerous factors that tend to increase the size of the $\mathbf{v}$ wave in mitral stenosis do not appear to make the onset of the wave any earlier. When mitral incompetence increases the height of the $\mathrm{v}$ wave the upstroke appears to start earlier and tends to obliterate the $\mathrm{x}$ descent. Thus the height of the peak of the $\mathrm{v}$ wave does not indicate the presence of incompetence but a rise of pressure at the time of the nadir of the $\mathbf{x}$ descent will indicate that incompetence is present.

There are other factors that might be important in this study. These are the left ventricular systolic pressure, the pulmonary artery pressure, the mitral valve size, and the presence of aortic valve disease. These factors have been considered and have been applied to the results without materially affecting them.

The degree of regurgitant flow has recently been estimated by a dye dilution technique (Korner and Shillingford, 1955). The disadvantage of this technique is that it does not distinguish between mitral and aortic incompetence. It would nevertheless provide a further method of establishing the value of atrial pressure curves in the diagnosis of mitral incompetence.

\section{SUMMARY}

Left atrial and left ventricular pressure tracings were taken at operations for mitral valvotomy and compared with the degree of mitral incompetence found by the surgeon. Fifty observations were made when there was mitral incompetence, and one hundred when there was stenosis without incompetence.

Three measurements suggested by previous workers were first examined: (i) height of the v wave, (ii) $\mathrm{v}-\mathrm{c}$ difference, and (iii) $\mathrm{Ry} / \mathrm{v}$ ratio. None of these proved of much value in identifying the presence of mitral incompetence. 
In contrast to these a new measurement has proved of value. This is termed the "corrected $x$ descent". It consists of the pressure at the nadir of the $x$ descent (or if this is absent the atrial pressure after the first third of ventricular systole) from which is subtracted (i) the atrial pressure just prior to the $\mathrm{c}$ or a wave and (ii) the extent of the $\mathrm{c}$ wave.

When the corrected $\mathrm{x}$ descent is over $5 \mathrm{~mm}$. $\mathrm{Hg}$ there is mitral incompetence; when it is under $5 \mathrm{~mm}$. $\mathrm{Hg}$ there is no severe incompetence, though there may be moderate incompetence.

I am grateful to Mr. O. S. Tubbs and Mr. I. M. Hill for permission to study the patients under their care and for their help in this study.

\section{REFERENCES}

Biörck, G., Axén, O., Krook, H., Andrén, L., and Wulff, H. B. (1953). Amer. Heart J., 45, 13.

Björk, V. (1955). Actor Chir. Scand., 107, 466.

Bloomfield, R. A., Lauson, H. D., Cournand, A., Breed, E. S., and Richards, D. W. (1946). J. clin. Invest., $25,639$.

Bücherl, E. (1956). Thoraxchirurgie, 4, 1.

Burchell, H. B., and Edwards, J. E. (1953). Circulation, 7, 747.

Dexter, L., Gorlin, R., Lewis, B. M., Haynes, F. W., and Harken, D. E. (1950). Transactions Amer. Clin. Climat. Assn., 62, 1.

Eliasch, H. (1952). Scand. J. Clin. Lab. Invest. Supp., 4, 1.

Fox, I. J., Wakai, C. S., Conolly, D. C., and Wood, E. H. (1956). Proc. Mayo Clinic, $31,126$.

Gérard, R., and Benyamine, R. (1956). Arch. Mal. Cour., 49, 31.

Gorlin, R., Lewis, B. M., Haynes, F. W., and Dexter, L. (1952). Amer. Heart J., 43, 357.

Haring, O. M., Liu, C. K., and Trace, H. D. (1956). Circulation Research, 4, 381.

Husfeldt, E., and Warburg, E. (1952). Medicinske Fremskridt, 2, 156.

Kent, E. M., Ford, W. B., Fisher, D. L., and Childs, T. B. (1955). Ann. Surg., $141,47$.

Korner, P., and Shillingford, J. (1955). Clin. Sci., 14, 553.

Lagerlöf, H., and Werkö, L. (1949). Scand. J. Clin. Lab. Invest., 1, 147.

Logan, A., and Turner, R. (1953). Lancet, 1, 1007.

McCord, M. C., and Blount, S. G. (1952). Amer. Heart J., 44, 671.

McGreggor, M., and Zion, M. M. (1955). Acta med. Scand. Supp., 306, 111.

Mackenzie, J. (1910). Diseases of the Heart. London. 2nd ed., p. 110.

Musser, B. G., Bougas, J., and Goldberg, H. (1956). Amer. Heart J., 52, 567.

Owen, S. G., and Wood, P. (1955). Brit. Heart J., 17, 41.

Soulié, P., Joly, F., Carlotti, J., and Sicot, J. R. (1954). Arch. Mal. Caur., 47, 1.

Venner, A., and Holling, H. E. (1953). Brit. Heart J., 15, 205.

Wade, G., Werkö, L., Eliasch, H., Gidlund, A., and Lagerlöf, H. (1952). Quart. J. Med., N.S., $21,361$.

Wiggers, C. J. (1923). Circulation in Health and Disease. London, p. 533.

$\longrightarrow$, and Feil, H. (1922). Heart, 9, 149.

Wynn, A., Matthews, M. B., and McMillan, I. K. R. (1952). Lancet, 2, 216. 